\title{
How to Use Modern Teaching Methods to Improve English Chinese Translation Ability
}

\author{
Weili Su \\ School of Foreign Languages and Culture, Beijing Wuzi University, Beijing, China \\ Email: suweili2007@163.com
}

How to cite this paper: Su, W.L. (2021) How to Use Modern Teaching Methods to Improve English Chinese Translation Ability. Open Access Library Journal, 8: e8279. https://doi.org/10.4236/oalib.1108279

Received: December 6, 2021

Accepted: December 27, 2021

Published: December 30, 2021

Copyright $\odot 2021$ by author(s) and Open Access Library Inc.

This work is licensed under the Creative

Commons Attribution International

License (CC BY 4.0).

http://creativecommons.org/licenses/by/4.0/ (c) (i) Open Access

\begin{abstract}
Modern educational technology is a theoretical and practical technology based on modern educational theory, which uses modern scientific and technological achievements and systematic science to improve teaching efficiency and optimize the process of education and teaching. It solves educational problems by studying the learning process and learning resources. Translation teaching is the cultivation of language comprehensive ability. The application of modern educational technology to translation teaching emphasizes the organization of teaching process and the optimization and coordination of teaching resources from the perspective of learners. It can greatly improve students' English-Chinese translation ability.
\end{abstract}

\section{Subject Areas}

Language Education

\section{Keywords}

Modern Educational Technology, Teaching Methods, Translation Ability, Modern Educational Theory, Learning Resources

\section{Introduction}

Modern educational technology is a theoretical and practical technology based on modern educational theory, using modern scientific and technological achievements and system science to improve teaching efficiency and optimize education and teaching process. It solves education and teaching problems by studying learning process and learning resources. The research object of educational technology is the learning process and learning resources. It emphasizes the use of systematic methods to organize the teaching process and optimize and coordinate the teaching resources from the perspective of learners. Modern 
educational technology can be divided into educational media technology and educational design technology. The former is a tangible materialized technology, which mainly involves the hardware and software technology in education, including the dissemination and transmission technology of educational information, the storage and retrieval technology of educational information, the processing technology of educational information and the display and copy technology of educational information; the latter is an invisible intelligent form of technology, which mainly involves how to select teaching materials and tools, arrange the planning and grouping of teaching activities, control, evaluation, management and strategy of teaching process, including educational system technology, educational psychological technology and educational planning technology.

Translation teaching is the cultivation of comprehensive language ability, which can not be formed overnight. It should be gradually realized through a large number of translation practice and the mastery of certain theories and skills. Translation teaching aims to strengthen the awareness of the comparison between the two languages and the deep understanding of the similarities and differences between the two language structures, strengthen the understanding of language and cultural background knowledge, strengthen the teaching and application of translation theories and skills, cultivate students' awareness and ability to skillfully use various translation skills, strengthen the training of students' basic language skills, and improve the accuracy of language understanding and expression. Applying modern educational technology to translation teaching can greatly improve students' English-Chinese translation ability [1].

\section{Changing the Role Orientation of Translation Teachers with Modern Educational Technology}

The wide application of modern educational technology in teaching undoubtedly brings new vitality and great impact to education, and puts forward higher requirements for teachers. It requires teachers not only to have profound professional knowledge, rich teaching experience and high teaching level, but also to have the thought and technology of modern education, to master the relevant knowledge of computer, multimedia and network teaching and the ability to use modern educational means and methods.

Internet and other network resources enable teachers and students, students and students to exchange information and learn from each other. Students can also use their spare time for individualized learning. The English teaching mode under modern educational technology requires teachers to change from the center of the teaching process to organizers, guides, helpers and evaluators [2].

To become the organizer of the teaching process, teachers must first do a good job in the curriculum design, including the learning objectives of the curriculum, the knowledge points of each chapter, the formulation of learning strategies, the selection of learning media, the content and methods of learning evaluation, the 
arrangement of learning process, the determination of learning themes, etc. Secondly, we should fully grasp the students' learning situation, including learning progress, learning effect and so on.

As a guide, teachers should clarify the learning objectives of translation, introduce learning contents, point out learning ways and guide learning methods, especially strengthen the guidance of learning methods under information technology. To carry out this task, teachers are required to the knowledge distribution, structure and learning methods of translation courses in the information-based learning environment, provide students with corresponding and effective learning ways according to different learning contents, understand the new problems existing in students' autonomous learning and cooperative learning, and give correct guidance in time. Teachers make use of online correcting homework and online thematic discussion to grasp students' learning situation in time and give help to students' online help respectively.

\section{Reforming Translation Teaching Content and Teaching System with Modern Educational Technology}

Making use of modern educational technology, teachers may strengthen translation teaching and translation research, track the frontier development of the discipline, update the teaching content, reform the teaching content and system. Making full use of the Internet and modern teaching means, they may compile electronic teaching plans and online courses, and establish teaching websites. Constantly updating the content of the website, they may provide electronic teaching plans and rich network resources, and facilitate students' independent learning. Compiling new translation teaching materials, strengthening the research of teaching methods, combining theory with practice, teachers may adapt to the development of translation teaching theory and translatology theory and the changes of students' and social needs with good teaching conditions. The teaching content has developed from a single translation skill training to a teaching mode of teaching modern translation theory and translation skills, highlighting the appreciation of excellent translation practice works, striving to broaden students' knowledge and cultivate their independent thinking ability, translation criticism ability and practical ability [3]. In the past, the teaching content mainly focused on the translation of political articles, literary works and poetry, especially Chinese-English translation, so that students lost many good opportunities to understand the external world through translation practice. With the continuous development of society, in order to meet the higher requirements of English Teaching in the 21st century, in addition to the teaching and training of translation skills, we should also increase the cultivation of cross-cultural communication awareness and ability, selecting various fresh articles close to modern life for students to translate, and designating a large number of excellent translations for them to appreciate and learn, so as to expand students' translation horizons and improve their ability to translate articles 
on various subjects.

\section{Improving Translation Teaching Methods and Means with Modern Educational Technology}

\subsection{Optimize Classroom Teaching}

Translation class needs to show students a large number of original texts. In traditional teaching, many teachers have to copy on the blackboard, which will waste valuable classroom time. Such problems can be effectively solved by using modern electronic technology. Teachers may carefully prepare electronic courseware in their extracurricular time, and fully prepare the original text and its translation, and a large number of background materials, relevant materials, interpretation materials, text materials and picture materials related to classroom teaching, using them immediately in class by projecting and demonstrating them, which is rich, clear, intuitive and vivid, thus receiving good teaching results. The real-time classroom teaching process and teaching content can also be recorded and saved for teachers and students.

\subsection{Explore Research-Based Translation Teaching}

In the past, translation teaching was limited to cramming classroom teaching. Using modern educational technology, we can explore research-based translation teaching, extend the classroom teaching place from the classroom to the library and reference room, and make students' learning rich, active and researching. The reference books used by students are expanded from one or several to encyclopedias, dictionaries and even dictionaries in several languages. In order to enable students to learn to use various reference books required for translation as soon as possible, teachers led students to the library and reference room to explain the search and use methods of different reference books in translation, answer various questions, explore with students. The old practice that students only rely on one or two English-Chinese and Chinese-English dictionaries for translation may be changed, enabling students to learn to use rich information resources. Accordingly, the classroom atmosphere is a state of discussion and research, rather than a simple full teacher's talking. Teachers may carry out interactive and heuristic teaching, discussing translation issues among teachers and students or among students on an equal footing, encouraging students to express their views, thus developing students' intelligent potential by jointly solving translation problems, and cultivating students' spirit of positive thinking, active exploration, serious research and innovation, and finally enabling students to develop a good style of study and translation [4].

\section{Using the Internet to Enrich Teaching Resources}

Translators are often at the forefront of knowledge and information exchange. In today's era of rapid development, due to explosive knowledge output and information renewal, new knowledge, new information, new materials, new words, 
new terms and new expressions emerge one after another and change with each passing day. The traditional paper tools and reference books often lag behind the development due to the limitations of publishing cycle and information exchange. Inevitably, there will be information gaps, especially in bilingual translation, there will be many blind spots. This problem, which is almost insurmountable in the traditional era, can be better solved in the Internet era. Translators can use the Internet to search and query. The translation of many new words can be easily solved with the help of the Internet. The Internet opens the door of translation assistance in the new era of translation. Using Internet retrieval, students can also obtain sufficient reference information in the judgment and selection of vocabulary, collocation, usage, language examples, frequency and the background of the original work, and have an objective grasp of the real state of the language, so as to obtain authentic translations [5]. Mastering the skills of using the Internet has become a compulsory content for students to learn and practice translation. We should pay attention to Internet assisted translation teaching, guide students to use the Internet in translation, and recommend websites including networks as the national translation qualification (level) examination, Google, Baidu, Yahoo, China translation network, China Translation Association, China translation research, China translators alliance, international translators alliance, etc.

\section{Conclusion}

The combination of modern information technologies such as multimedia and network technology and the translation teaching mode of "student-centered and teacher led" provides students with a broad, flexible and creative learning space [6] for learning translation. In the process of translation teaching, teachers should be exploring and innovative, learn the latest translation theory and multimedia network technology knowledge, give full play to the functions of teachers' as organizers, coordinators, helpers and guides, always explore new translation teaching methods and teaching strategies by using modern teaching means, constantly update teaching contents, using network resources to broaden students' horizons and knowledge, train their translation skills and improve their translation ability.

\section{Conflicts of Interest}

The author declares no conflicts of interest.

\section{References}

[1] Guo, J. (2001) Cultivation of Translation Ability in College English Teaching. Journal of Changde Normal University (Social Science Edition), No. 3, 13-15.

[2] Wang, Q. (2007) Orientation of Teacher's Role in College English Autonomous Learning Classroom Model. Journal of Chongqing University of Posts and Telecommunications (Social Sciences Edition), No. 1, 125-127.

[3] Yang, R. (2010) Translation Competence Development in College English Transla- 
tion Teaching. Neijiang Science and Technology, No. 6, 33-35.

[4] Zhou, J. (2011) Effective Ways to Improve Students' Translation Ability in English Teaching. Modern Communication, No. 4, 44-46.

[5] Sun, N. (2010) The New Trend of Translation Teaching Model-A Preliminary Study of Competence-Centered Translation Teaching Model. Private Science and Technology, No. 12, 58-61.

[6] Su, W.L. (2021) How to Use Modern Teaching Methods to Cultivate Students' Autonomous Learning Ability. Open Access Library Journal, 8, 1-5.

https://doi.org/10.4236/oalib.1107232 